Article

\title{
Development of an Energy Biorefinery Model for Chestnut (Castanea sativa Mill.) Shells
}

\author{
Alessandra Morana ${ }^{1}$, Giuseppe Squillaci ${ }^{1}$, Susana M. Paixão ${ }^{2}$, Luís Alves ${ }^{2}$, Francesco La Cara ${ }^{1}$ \\ and Patrícia Moura $2, *$ \\ 1 Institute of Agro-Environmental and Forest Biology, National Research Council of Italy, \\ Via Pietro Castellino 111, 80131 Naples, Italy; alessandra.morana@ibaf.cnr.it (A.M.); \\ giuseppe.squillaci@ibaf.cnr.it (G.S.); francesco.lacara@ibaf.cnr.it (F.L.C.) \\ 2 LNEG, Laboratório Nacional de Energia e Geologia, Unidade de Bioenergia, Estrada do Paço do Lumiar, \\ 1649-038 Lisboa, Portugal; susana.alves@lneg.pt (S.M.P.); luis.alves@lneg.pt (L.A.) \\ * Correspondence: patricia.moura@lneg.pt; Tel.: +351-210-924-600; Fax: +351-217-163-163
}

Received: 11 August 2017; Accepted: 22 September 2017; Published: 27 September 2017

\begin{abstract}
Chestnut shells (CS) are an agronomic waste generated from the peeling process of the chestnut fruit, which contain $2.7-5.2 \%(w / w)$ phenolic compounds and approximately $36 \%(w / w)$ polysaccharides. In contrast with current shell waste burning practices, this study proposes a CS biorefinery that integrates biomass pretreatment, recovery of bioactive molecules, and bioconversion of the lignocellulosic hydrolyzate, while optimizing materials reuse. The CS delignification and saccharification produced a crude hydrolyzate with $12.9 \mathrm{~g} / \mathrm{L}$ of glucose and xylose, and $682 \mathrm{mg} / \mathrm{L}$ of gallic acid equivalents. The detoxification of the crude CS hydrolyzate with $5 \%(w / v)$ activated charcoal (AC) and repeated adsorption, desorption and AC reuse enabled $70.3 \%(w / w)$ of phenolic compounds recovery, whilst simultaneously retaining the soluble sugars in the detoxified hydrolyzate. The phenols radical scavenging activity (RSA) of the first AC eluate reached $51.8 \pm 1.6 \%$, which is significantly higher than that of the crude CS hydrolyzate $(21.0 \pm 1.1 \%)$. The fermentation of the detoxified hydrolyzate by C. butyricum produced $10.7 \pm 0.2 \mathrm{mM}$ butyrate and $63.9 \mathrm{~mL} \mathrm{H}_{2} / \mathrm{g}$ of CS. Based on the obtained results, the CS biorefinery integrating two energy products $\left(\mathrm{H}_{2}\right.$ and calorific power from spent CS), two bioproducts (phenolic compounds and butyrate) and one material reuse (AC reuse) constitutes a valuable upgrading approach for this yet unexploited waste biomass.
\end{abstract}

Keywords: waste biomass; chestnut shells; fermentative hydrogen; bioactive compounds; polyphenols; antioxidant activity; butyrate

\section{Introduction}

Lignocellulosic biomass (LB) represents an attractive and renewable resource for the production of biofuels, chemicals, and polymers [1]. This biomass comprises energy crops and residues from agriculture and forestry, which can significantly contribute to the future global energy supply without competing with food sources [2]. Every year, thousands of tons of agro-forestry wastes are generated in Europe, creating severe disposal problems and environmental contamination [3]. Accordingly, one of the current challenges is to find attractive solutions for the rational exploitation of this LB to obtain a double beneficial effect: (i) production of valuable compounds, such as sugars, that can be used for biofuels, polymers and fibers, and bioactive compounds for the food, cosmetic and pharmaceutical industries [4-6]; and (ii) elimination of wastes, which represent a source of pollution. These goals can be reached under a biomass-based refinery framework where, analogously to a petroleum refinery, a multiplicity of biofuels, bioenergy vectors and products can be produced from the as much as possible full utilization of the biomass feedstock [7]. 
Chestnut tree (Castanea sp.) is recognized as one of the most remarkable trees in the world due to its economic importance. Its natural distribution includes three major geographical areas in the world: Asia, with China and South Korea as the world's leading producers; North America; and Europe, with the European Union countries supplying 10\% of the global chestnut fruit production [8]. In 2014, about 187,500 tons of chestnuts were produced and processed in the Mediterranean basin, with Italy, Greece and Portugal representing the main European producers [9]. In particular, they generate $42 \%, 23 \%$, and $15 \%$ of the total European Union chestnut fruit production, respectively. In Portugal, the chestnut production importantly contributes to enhance the balanced development of the territory, as it has a major macroeconomic significance at a regional scale [10]. Through the peeling process, the chestnut industry produces a large amount of a solid residue which represents approximately $10-15 \%$ by weight of the chestnut [11]. The most significant fraction of this solid residue is constituted by outer and inner shells, which nowadays are burned as fuel in the industrial plant to overcome disposal problems. However, this practice can create environmental problems because several toxic compounds may be produced, with some of them similar to dioxins (e.g., CO, NOx, long-chain/aromatic hydrocarbons, polychlorodibenzodioxins) $[12,13]$. Outer and inner chestnut shells (CS) contain 2.7-5.2\% (w/w) of phenolic compounds, which exhibit antioxidant activity [14-18], and about $36 \%(w / w)$ of sugars as polysaccharides [19] that can be used as feedstock for biofuels production. According to the chestnut production in 2014, approximately $18,750-28,125$ tons of solid residues were generated in the Mediterranean basin, which corresponded to about 6750-10,125 tons of polysaccharides $[9,11,19]$. These residues represent a major utilizable bioresource until now not fully exploited for eco-sustainable solutions.

Chestnut shells constitute a potential feedstock for the fermentative production of energy vectors and bioproducts. Dark Fermentation (DF) in particular enables the production of hydrogen $\left(\mathrm{H}_{2}\right)$ and organic acids from the most diverse biomass feedstock, and theoretically any sugar-containing biomass can be used as fermentation substrate [20]. Brewery's spent grain, bagasse and Jatropha hulls are examples of raw materials that have proven their suitability for similar purposes [21,22], but the potential of CS as a valuable feedstock for DF has yet to be evaluated. From previous works, cellulose and xylan were found to be the main polysaccharides present in CS and they can be effectively hydrolyzed ( $>67 \%$ saccharification yield) to fermentable sugars [19]. Clostridium species have been preferentially used for the bioconversion of these hydrolyzates because of their plain medium requirements and comparatively high product yields [23]. Clostridium butyricum is able to ferment complex substrates to $\mathrm{H}_{2}$ and butyric acid and to tolerate wide $\mathrm{pH}$ ranges [24], which is an advantage in the implementation of low-cost and big-scale conversion processes for platform chemicals and/or biofuels production. In particular, butyric acid is industrially produced via a chemical synthesis involving the oxidation of butyraldehyde, which is obtained from propylene derived from crude oil [25]. To reduce the fossil fuels dependence, this acid can be alternatively produced by DF. For this purpose, the biorefinery model proposed in the present work integrated one detoxification stage with activated charcoal (AC) upstream to DF to adsorb the polyphenols in the CS hydrolyzate. This provides the double advantage of recovering valuable bioactives but also potentially avoiding inhibitory effects of the phenolic compounds on microbial growth [26,27]. Phenolic compounds are well known as natural powerful antioxidants. They are found in a variety of foods and herbs, and can have potential applications in the food and pharmaceutical industries [11,16,17,28-30]. The production of bioactives is expected to increase the overall economic revenue and boost the CS biorefinery main route for bioenergy production.

The goal of the present work was to develop a biorefinery model for the upgrading of CS which could take the best advantage of the chemical composition of this waste biomass. The proposed model targeted the production of $\mathrm{H}_{2}$ and bioactive compounds, the regeneration of $\mathrm{AC}$ as detoxification agent, and the potential of the spent CS for heat and power generation. To the best of our knowledge, there is still no report of a CS biorefinery model that represents an efficient arrangement of waste 
biomass pretreatment, saccharification, bioconversion, materials reuse and process integration, tendentiously oriented for zero-waste and circular economy purposes.

\section{Results and Discussion}

\subsection{Chemical Characterization of Crude and Pretreated CS}

The major components of crude CS were Klason lignin $(41.7 \pm 0.6 \%$ CS dry weight $)$ and carbohydrates (41.6\% CS dry weight), from which cellulose was the major representative $(28.4 \pm 0.8 \%$ as glucose) followed by xylan $(7.9 \pm 0.9 \%$ as xylose). Galactose $(2.8 \pm 0.1 \%)$, arabinose $(2.2 \pm 0.3 \%)$, and cellobiose $(0.3 \pm 0.02 \%)$ were also present. Due to its recalcitrant nature, LB is usually submitted to a pretreatment stage to improve the accessibility of the lignocellulosic matrix to the enzymes [31]. Accordingly, CS were soaked in aqueous ammonia $(5 \% w / v)$ for alkaline pretreatment. The Klason lignin decreased to $17.1 \pm 0.6 \%$ dry weight of the pretreated CS, and cellulose and xylan, quantified as glucose and xylose, accounted for $40.6 \pm 1.2 \%$ and $12.8 \pm 1.3 \%$ dry weight of the pretreated solids, respectively. Galactose, arabinose and cellobiose were rinsed from the pretreated CS by the washing necessary to correct the biomass $\mathrm{pH}$ to the required value $(\mathrm{pH} 5.0)$.

\subsection{Saccharification of CS and Detoxification with Activated Charcoal}

For the saccharification, the pretreated CS were incubated with a cocktail prepared with a commercially available cellulase, xylanase and beta-glucosidase as described elsewhere [19]. After $72 \mathrm{~h}$ incubation at $50{ }^{\circ} \mathrm{C}$ and centrifugation, $96 \%$ of the supernatant volume, or CS hydrolyzate, was recovered. The concentrations of glucose and xylose in the hydrolyzate were 8.67 and $4.25 \mathrm{~g} / \mathrm{L}$, respectively, whereas the total phenolic content was $682 \mathrm{mg}$ Gallic Acid Equivalents (GAE)/L. After the enzymatic digestion of cellulose and hemicelluloses, the resulting hydrolyzate may contain molecules such as organic acids, furans, and phenolic compounds that often act as inhibitors of microbial growth in the subsequent fermentation stage, thus lowering the biofuel production yield [32,33]. Consequently, the hydrolyzates need to be detoxified before fermentation. Several procedures have been described for the removal of inhibitory compounds from LB hydrolyzates in order to limit their negative action on the fermentation [34]. Among these, the extraction with ethyl acetate [35], ion exchange [36], AC adsorption [37] or biological treatments with microorganisms and enzymes [38] can be referred. The treatment with AC is considered an effective method for the removal of phenolic compounds from LB hydrolyzates because of the large surface area of the charcoal particles, high adsorption capacity, and availability [36]. In addition, because some of these potential inhibitory molecules possess strong antioxidant power, their subsequent desorption from charcoal enables the recovery of bioactive compounds that can be further utilized for value-added applications $[18,28,30,33,39]$. In our experiments, different concentrations of AC were tested to obtain a substantial removal of phenolic compounds, but at the same time minimizing the loss of fermentable sugars. Although a complete removal of phenolic molecules from the hydrolyzate was achieved by using $20 \%(w / v)$ AC, a significant decrease in glucose and xylose concentration was also registered ( $46.5 \%$ and $54 \%(w / v)$, respectively) (Figure 1). The detoxification with $5 \%(w / v)$ AC produced the best compromise, retaining $93.7 \%(w / v)$ glucose, $100 \%(w / v)$ xylose and only $23 \%(w / v)$ phenolic compounds in the detoxified hydrolyzate. 


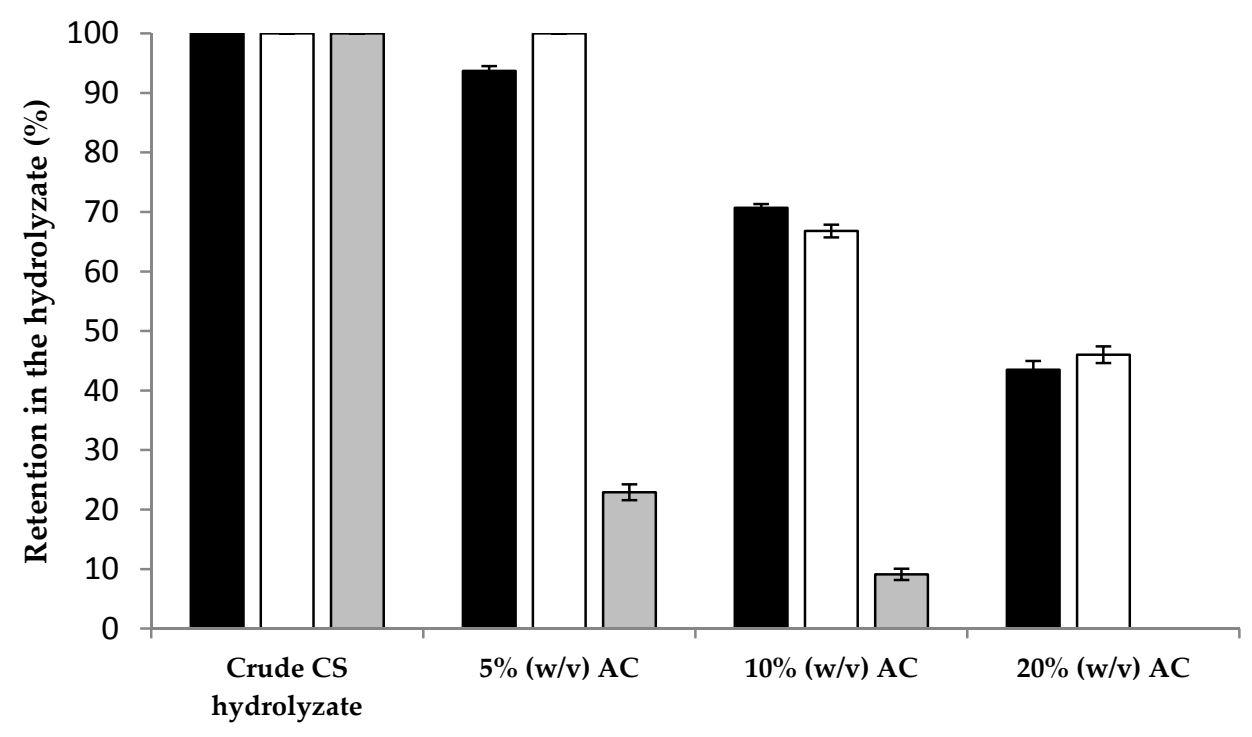

Figure 1. Retention of sugars and phenolic compounds in the CS hydrolyzate, before and after detoxification with AC at 5, 10 and 20\% $(w / v)$. Standard deviation $(n=3)$ is indicated by the error bars (glucose, black; xylose, white; total phenols, grey).

\subsection{Desorption of Phenolic Compounds from Activated Charcoal and Radical Scavenging Activity}

Phenolic compounds are molecules with well-recognized biological properties such as antioxidant, antimicrobial, anti-inflammatory and anticancer activities [40-42]. Consequently, their recovery from AC is a desirable target, especially because they have impact on the economic interests of the food, pharmaceutical and cosmetic industries. The desorption of the phenolic compounds from $5 \%(w / v)$ AC after detoxification of the CS hydrolyzate was tested with several eluent mixtures containing alcoholic or alkaline solutions. Sodium hydroxide, water and alkaline ethanol were chosen according to previous desorption experiments [43-45]. Ozkaya [44] recovered $61 \%$ of the phenolic molecules adsorbed on charcoal by using $0.15 \mathrm{M}$ sodium hydroxide, but the further increase of the eluent alkaline concentration did not lead to additional desorption. Conversely, $99 \%$ recovery was achieved by Qadeer and Rehan [45] by using $0.5 \mathrm{M}$ sodium hydroxide for desorption of a mixture of phenol, pyrogallol, picric and salicylic acids from charcoal. These results allowed us to suppose that the capability to reach a significant recovery yield depends not only from the eluent but also from the type of phenolic molecules. Therefore, in the present study, higher concentrations of sodium hydroxide were tested, in addition to a mixture composed of sodium hydroxide and ethanol to investigate possible synergic effects. Water was used as reference and produced the lowest desorption yield (only $7.3 \%$ of the total phenolic compounds adsorbed on AC were effectively desorbed) (Figure 2). The highest desorption yield (65.3\%) was obtained when AC was treated with $2 \mathrm{M}$ sodium hydroxide/ethanol (1:1 $v / v)$ for $2 \mathrm{~h}$ at $70{ }^{\circ} \mathrm{C}$, in the first elution (Elution I).

Indeed, with the objective to increase the recovery of phenolic molecules through the elution with $2 \mathrm{M}$ sodium hydroxide/ethanol, AC was further submitted to a second elution step (Elution II). The findings indicated that the majority of the phenolic compounds were already desorbed by the first elution, and only a small additional amount was detected in the second eluate (Table 1). The total concentration of recovered bioactive compounds was $369.6 \pm 11.5 \mathrm{mg} \mathrm{GAE} / \mathrm{L}$, which corresponded to $70.3 \%$ of the total phenolic molecules adsorbed on AC.

The desorbed phenolic molecules were characterized in terms of antioxidant power. More in detail, their radical scavenging activity (RSA) was measured by the 2,2-diphenyl-1-picrylhydrazyl (DPPH) assay (Section 3.7), and samples from the elution I and II showed a RSA of $51.8 \pm 1.6 \%$ and $26.0 \pm 0.9 \%$, respectively (Table 1). These values were higher than the RSA calculated for the crude CS hydrolyzate $(21.0 \pm 1.1 \%)$ despite its higher phenolic content $(682.0 \pm 16.9 \mathrm{mg} \mathrm{GAE} / \mathrm{L})$. These findings support the 
hypothesis that the detoxification and the elution processes operated a selection of molecules provided with stronger antiradical activity.

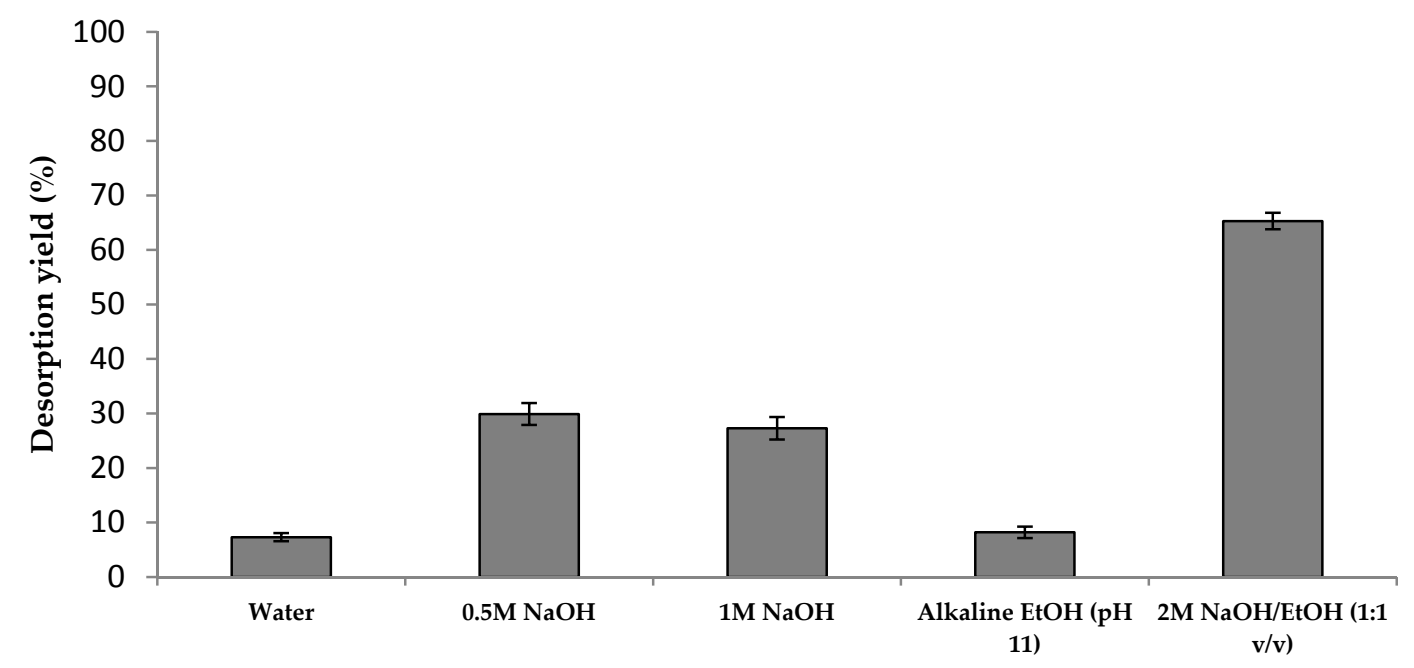

Figure 2. Desorption yield of phenolic molecules from 5\% (w/v) AC, after CS hydrolyzate detoxification, testing several eluent mixtures containing alcoholic or alkaline solutions. Standard deviation $(n=3)$ is indicated by the error bars.

Table 1. Phenolic compounds desorption from activated charcoal (AC) and radical scavenging activity (RSA). The phenolic compounds were eluted from AC with $2 \mathrm{M} \mathrm{NaOH} /$ ethanol $(1: 1 v / v)$. The eluates and the hydrolyzate, containing $20 \mu \mathrm{g}$ GAE, were analyzed for RSA (Section 3.7).

\begin{tabular}{cccc}
\hline Sample & $\begin{array}{c}\text { Adsorbed Phenolic } \\
\text { Compounds (mg GAE/L) }\end{array}$ & $\begin{array}{c}\text { Desorbed Phenolic } \\
\text { Compounds (mg GAE/L) }\end{array}$ & RSA (\%) \\
\hline CS hydrolyzate & - & - & $21.0 \pm 1.1$ \\
Activated charcoal & $525.8 \pm 15.6$ & - & - \\
Elution I & $182.5 \pm 6.2$ & $343.4 \pm 13.2$ & $51.8 \pm 1.6$ \\
Elution II & $156.2 \pm 8.8$ & $26.3 \pm 2.3$ & $26.0 \pm 0.9$ \\
Total (Elution I + II) & - & $369.6 \pm 11.5$ & - \\
\hline
\end{tabular}

As already mentioned, AC is widely used for detoxification of several kinds of samples, such as LB hydrolyzates and wastewaters [46], but there are only few reports about the recovery of the adsorbed molecules for subsequent use. Our method not only removed potential fermentation inhibitors from the CS hydrolyzate, but also concentrated molecules with high antioxidant power in the eluate from Elution I.

\subsection{Fermentative Hydrogen and Butyrate Production}

The CS hydrolyzate obtained after $5 \%(w / v)$ AC detoxification was tested as substrate for the fermentative $\mathrm{H}_{2}$ production by $C$. butyricum. This microorganism is a recognized $\mathrm{H}_{2}$ producer from a diversity of substrates, such as LB and microalgal biomass $[47,48]$. The fermentation results are summarized in Table 2. In batch fermentations, $\mathrm{H}_{2}$ evolution tends to follow a sigmoidal profile, starting when the cells are at the exponential growth mid-stage [49]. The maximum $\mathrm{H}_{2}$ production is generally achieved at the beginning of the stationary phase. A maximum cumulative $\mathrm{H}_{2}$ production of $1598 \pm 100 \mathrm{~mL} / \mathrm{L}$ was reached after $12 \mathrm{~h}$ of incubation, corresponding to $96.8 \%$ consumption of the total sugars, which indicates a high metabolic activity of $C$. butyricum and a good adaptation to the CS hydrolyzate. In a fermentation experiment with C. butyricum CGS5, Lo et al. [47] obtained a cumulative $\mathrm{H}_{2}$ production of $1006 \mathrm{~mL} / \mathrm{L}$ from an acid hydrolyzate of alkaline pretreated rice straw. 
Table 2. Sugars consumption, $\mathrm{H}_{2}$ and organic acids production in the fermentation of detoxified CS hydrolyzate by $C$. butyricum.

\begin{tabular}{cc}
\hline Parameter & Result \\
\hline Cumulative $\mathrm{H}_{2}$ production $(\mathrm{mL} / \mathrm{L})$ & $1598 \pm 100$ \\
Hydrogen yield $(\mathrm{mL} / \mathrm{g} \mathrm{CS})$ & $63.9 \pm 4.0$ \\
$\mathrm{H}_{2} / \mathrm{CO}_{2}$ ratio $(\mathrm{mol} / \mathrm{mol})$ & $1.4 \pm 0.1$ \\
Acetate production $(\mathrm{mM})$ & $13.3 \pm 1.6$ \\
Butyrate production $(\mathrm{mM})$ & $10.7 \pm 0.2$ \\
Formate production $(\mathrm{mM})$ & $6.9 \pm 0.2$ \\
Total sugars consumption $(\%)$ & $96.8 \pm 0.7$ \\
\hline
\end{tabular}

An alternative way to report the suitability of LB for fermentative $\mathrm{H}_{2}$ production is the estimation of the $\mathrm{H}_{2}$ production yield per mass unit of $\mathrm{CS}$ dry weight. This estimation of the conversion efficiency incorporates the variables associated with the complexity of the LB, the bioconversion efficiency, and the type of pretreatment applied, which can be performed under more or less environmental harsh conditions. In the present study, $50 \mathrm{~g} / \mathrm{L}$ of CS were used in the preparation of the hydrolyzate and the $\mathrm{H}_{2}$ yield reached $63.9 \mathrm{~mL} / \mathrm{g}$ CS. This value is comparable to $60.2 \mathrm{~mL} \mathrm{H}_{2} / \mathrm{g}$ obtained in the fermentation of acid treated soybean straw by an enriched mixed culture dominated C. butyricum [50]. However, according to Kumar et al. [51] the results in the literature diverge widely, from 31.6 to $176 \mathrm{~mL} \mathrm{H}_{2}$ /g biomass dry weight, and comparisons are sometimes difficult due to the variable lignin, cellulose and hemicelluloses ratios in the lignocellulosic matrix and to the diversity and efficiency of possible pretreatment and saccharification combinations.

The fermentation of CS hydrolyzate by C. butyricum led to the production of soluble metabolites, from which acetate and butyrate were the most representative. Butyrate amounted to $45 \%(w / v)$ of the total organic acids produced, and achieved a maximum concentration of $10.7 \pm 0.2 \mathrm{mM}$ (Table 2) after $12 \mathrm{~h}$ of incubation. This is equivalent to $18.9 \mathrm{mg}$ butyrate/g CS and would correspond to a potential daily production of $0.4 \mathrm{mmol} / \mathrm{g}$ day. Bastidas-Oyanedel et al. [52] referred butyric acid as the highest valuable compound produced in DF. The reason for this are the numerous applications for butyric acid in the chemical, textile, plastic, food, beverage, dairy and pharmaceutical industries [53]. Bioplastics in particular have attracted widespread attention as eco-friendly alternative to conventional plastics, and its production opens new perspectives for organic acids use. More recently, interest in butyric acid as precursor for the synthesis of butanol and butyl esters to be used as drop-in biofuels has also been raised [54]. The maximization of butyrate production under a biorefinery framework would thus have the potential to advantageously boost the overall process revenue.

\subsection{CS Biorefinery Model}

Based on the obtained results of CS upgrading for the production of bioenergy vectors and bioactive compounds, a CS biorefinery model was proposed (Figure 3). The biorefinery mass flows were planned to take advantage of the chemical composition of CS, and to highlight a full range of possible conversion, integration and reuse possibilities. The proposed flows are non-concurrent or even mutually favorable and can be simultaneously conducted. However, depending on the biorefinery set-up, process optimization can prioritize some products in detriment of others. For example, the hydrolyzate detoxification with AC for the subsequent recovery of antioxidants favors the fermentative $\mathrm{H}_{2}$ production by the removal of possible microbial inhibitors. Conversely, the simultaneous optimization of DF for the production of $\mathrm{H}_{2}$ and butyrate is difficult. This is because the theoretical yield of $\mathrm{H}_{2}$ production is $2 \mathrm{~mol} / \mathrm{mol}$ hexose when butyrate is the main organic acid produced. This yield increases to $4 \mathrm{~mol} / \mathrm{mol}$ hexose if all the substrate would be converted to acetate [55]. 


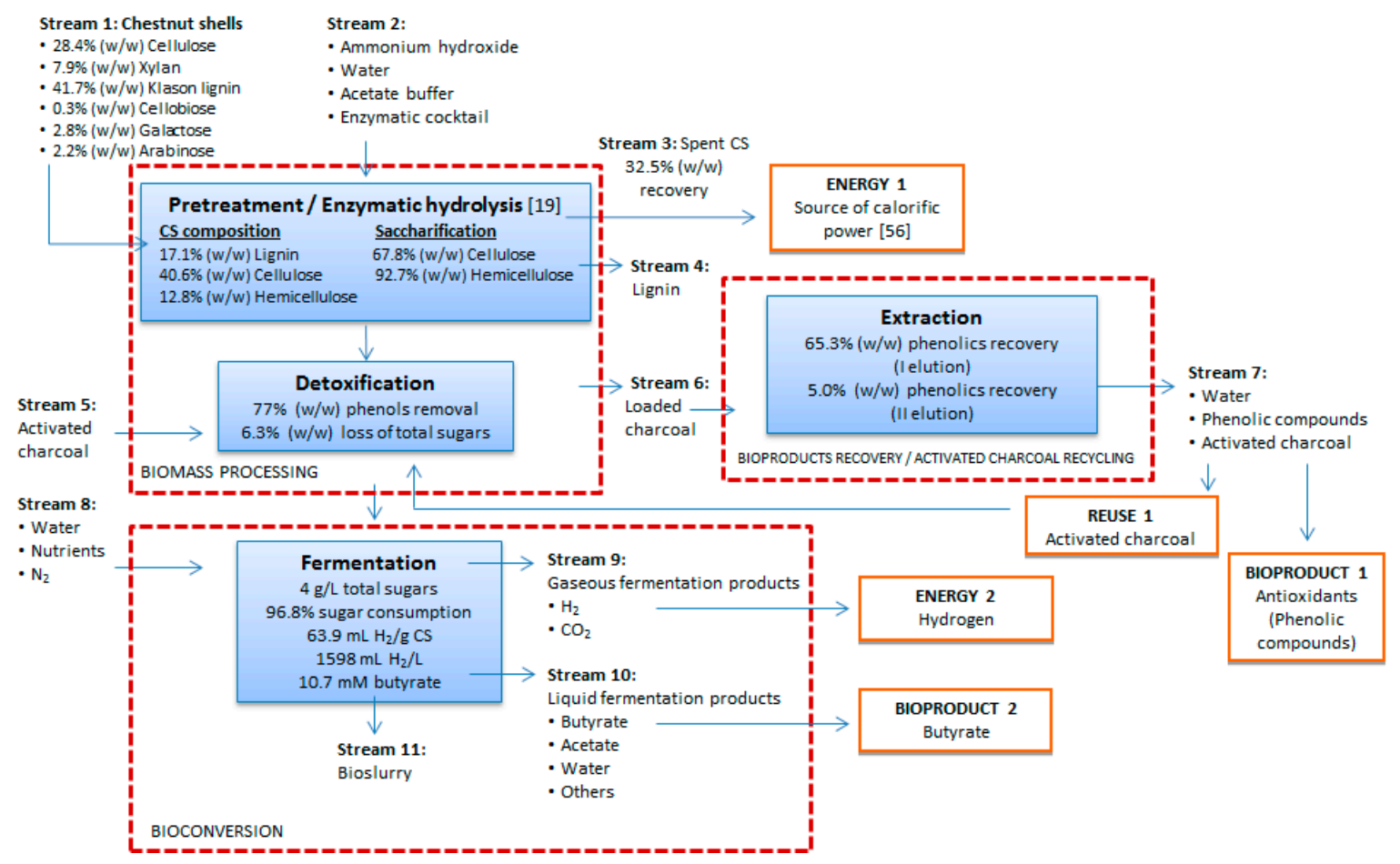

Figure 3. Chestnut shells biorefinery model.

The model proposed in Figure 3 integrates 11 streams that are meant to represent all the possible inputs, mass flows and outputs that may be included in the CS biorefinery, as a global portfolio view of possibilities. As depicted, the biorefinery streams for energy production include the use of spent CS as source of calorific power (ENERGY 1) and the fermentative $\mathrm{H}_{2}$ production (ENERGY 2). The streams for bioactives encompass the recovery of phenolic compounds as antioxidants (BIOPRODUCT 1) and the production of butyrate (BIOPRODUCT 2), which generally brings added-value to the main branch of energy production. The biorefinery model can be optimized in terms of process costs and waste generation, and this is reflected in the recovery and reuse of the AC (REUSE 1) from the adsorption/desorption of the phenolic compounds. In more detail, the main outputs in Figure 3 include:

- ENERGY 1: Biomass can be converted into energy (heat or electricity) through combustion, a process which is the most widely applied because of its low cost. The gross calorific values of chestnut shell and chestnut shell biochar are 15.49 and $25.86 \mathrm{MJ} / \mathrm{kg}$, respectively [56]. Although it is expected that the chemical composition of spent CS, namely the final residue obtained after pretreatment and saccharification of CS, is somewhat different from crude CS or CS biochar, its use can be taken in consideration for energy production. As spent CS represent $32.5 \%(w / w)$ of the initial CS biomass (Figure 3), about 6100-9140 tons/year could be obtained from the total shell waste solid residue produced in 2014 in the Mediterranean basin.

- ENERGY 2: The price of conventionally produced $\mathrm{H}_{2}$ in 2016 averaged $4.0 \mathrm{USD} / \mathrm{kg} \mathrm{H}_{2}$ in the USA, whereas the costs for the fermentative $\mathrm{H}_{2}$ production are currently estimated on $578 \mathrm{USD} / \mathrm{kg} \mathrm{H}_{2}$ [57]. According to this reference, the high costs of the fermentative process are associated with a low molar yield and a low concentration of carbohydrates in the fermentation broth, which is adequate for research scale but not to scale-up to an industrial process. In fact, assuming the production yield obtained in the present work $\left(63.9 \mathrm{~mL} \mathrm{H}_{2} / \mathrm{g}\right)$, the total amount of CS generated in 2014 in the Mediterranean region would only correspond to 106,975-160,463 kg of $\mathrm{H}_{2}$. The feedstock cost and the capital cost for the industrial production are also critical to the high projected cost of hydrogen generated via DF of biomass. However, in the case of CS as waste biomass, the negative feedstock cost would impact positively on the process economic balance, 
so as the co-production of bioactive molecules. Considering an optimized scenario modeled with a fermentation broth concentration of $300 \mathrm{~g} / \mathrm{L}$ and the conversion of excess lignin and biogas to thermal energy and further to electrical energy, a more competitive cost of 3.78 to $5.47 \mathrm{USD} / \mathrm{kg}$ $\mathrm{H}_{2}$ can be achieved [57].

- PRODUCT 1: Phenolic compounds belong to the wide class of phytonutrients, and find application in a variety of sectors such as food, feed, pharmaceutical and cosmetic industry. As they originate from natural sources, the diversity of biomolecules that can be obtained and the respective prices vary greatly, also depending on their purity and biological activity. The price of gallic and ellagic acids, two phenolic compounds present in chestnut extracts, is approximately 645 and $52,000 \mathrm{USD} / \mathrm{kg}$, respectively (Sigma-Aldrich Company, Milano, Italy). The market of phenolic compounds is much diversified as they can be commercialized either as pure compounds or mixture of natural origin. In 2014, the global market of phytonutrients was estimated at 3.05 Billion USD and it is foreseen to reach 4.63 Billion USD within 2020, with Europe expecting to be the fastest-growing market in the near future [58]. As the amount of the phenolic compounds recovered from the hydrolyzate corresponds to the $0.74 \%(w / w)$ of the crude CS, it would be expected that about $138,600-207,900 \mathrm{~kg}$ /year could be obtained from CS.

- PRODUCT 2: The price of butyric acid is currently approximately 2000-2500 (USD/ton) [53], which represents an attractive income when transposed to the potential butyrate production from CS. Due to the variety of industrial applications for this organic acid, to the need to set aside petrochemicals based production processes, along with the newly explored pathways for the production of drop-in biofuels, the market size for butyrate was estimated in 30,000 (ton/year) in 2015 and in general "green" volatile fatty acids production exhibits a tendency to expand [59]. Using the butyrate production yield obtained in the present work $(10.7 \mathrm{mM})$ and the amount of shell residues generated by the Mediterranean chestnut industry in 2014 (18,750-28,125 tons), it is possible to estimate a potential of $353,541-530,312 \mathrm{~kg}$ for butyrate production.

- REUSE 1: To become economically attractive, a detoxification process based on the use of an adsorbent matrix must foresee the reutilization of the adsorbent for additional cycles. As such, after the phenols desorption stage, AC can be reused for detoxification of a fresh hydrolyzate followed by phenolic compounds elution. This practice provides an environmental gain by avoidance of AC disposal. Additionally, the prospect of selectively recovering CS phenolic compounds with different antioxidant activities, as suggested by the RSA of the eluates from Elution I and II, is of major interest and deserves further investigation.

\section{Materials and Methods}

\subsection{Chemicals}

Folin-Ciocalteu reagent, sodium carbonate, gallic acid, DPPH, glucose, xylose, fucose, sodium hydroxide, and ammonium hydroxide were purchased from Sigma-Aldrich Company (Milano, Italy). Methanol was from Carlo Erba Reagents (Milano, Italy), and ethanol from Romil Ltd (Cambridge, UK). Activated charcoal was from Merck (Darmstadt, Germany) and the remaining reagents were of the highest grade commercially available.

\subsection{Biorefinery Stages}

The biorefinery model proposed for CS was based on the following stages, according to Figure 4: (i) CS alkaline pretreatment [19]; (ii) enzymatic hydrolysis of CS; (iii) detoxification of the crude CS hydolyzate with AC; (iv) recovery of phenolic compounds from AC; (v) recycling and reuse of AC; and (vi) fermentation of the detoxified CS hydrolyzate by C. butyricum. The outputs in bioproducts and bioenergy comprise: (i) phenolic compounds with antioxidant potential desorbed from AC; (ii) hydrogen produced from CS hydrolyzate; (iii) butyrate produced from CS hydrolyzate; (iv) heat or electricity produced from spent CS combustion [57]; and (v) recycled AC. 


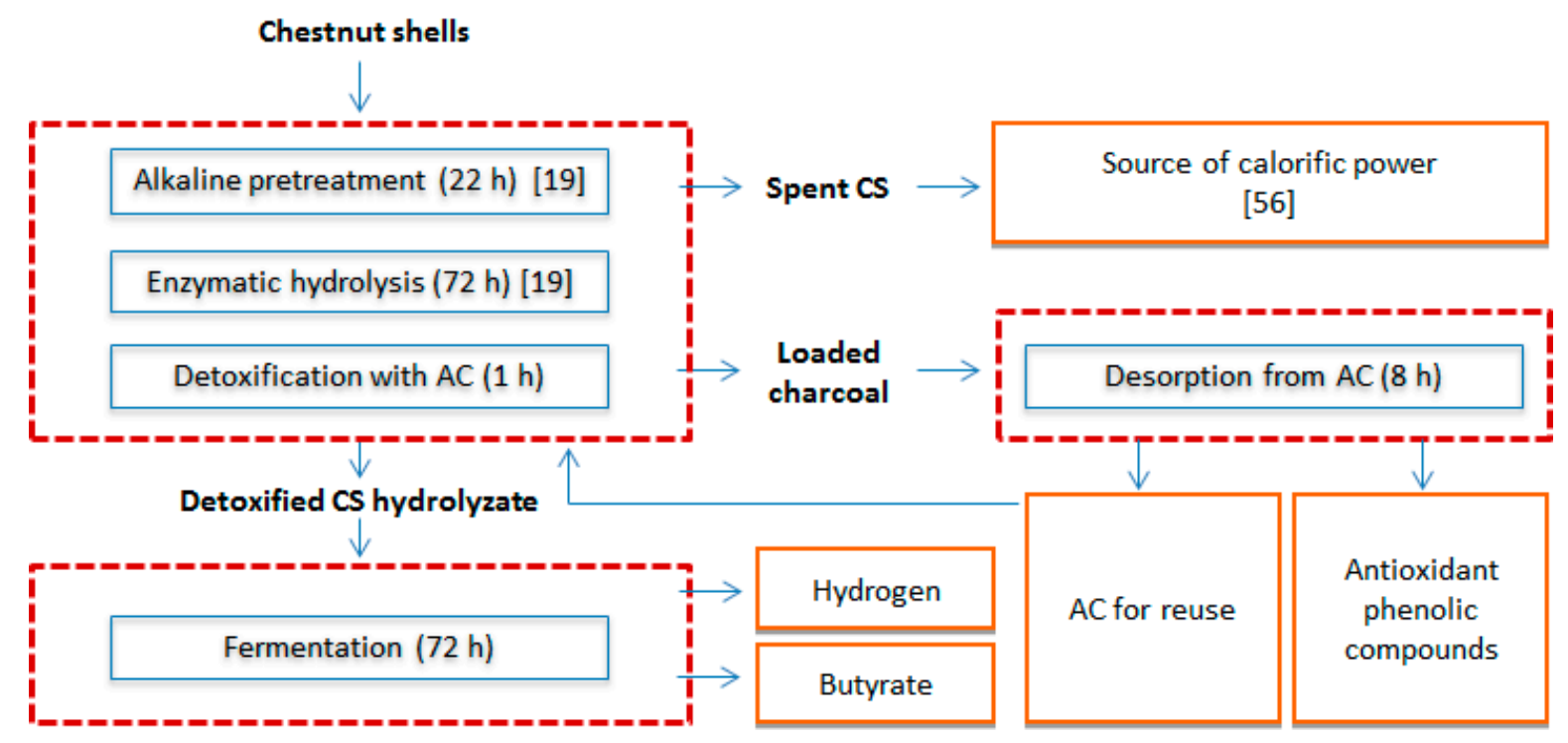

Figure 4. CS biorefinery stages, bioproducts and energy outputs.

\subsection{Pretreatment and Saccharification of CS}

The chemical characterization of crude and pretreated CS, and the pretreatment by aqueous ammonia soaking method to facilitate the release of fermentable sugars were previously reported [19]. For saccharification, $4 \mathrm{~g}$ of pretreated CS at $5 \%(w / v)$ solid loading were supplemented with a cocktail of the following commercial preparations in $50 \mathrm{mM}$ sodium acetate buffer, $\mathrm{pH}$ 5.0: Accellerase 1500 (528 units of cellulase), Accellerase XY (17,536 units of xylanase), and Accellerase BG (32,656 units of beta-glucosidase) (Danisco US Inc., Genencor Division, Palo Alto, CA, USA). The saccharification was carried out in a shaking water bath at $50{ }^{\circ} \mathrm{C}$ and $140 \mathrm{rpm}$ for $72 \mathrm{~h}$. After this time, the mixture was chilled on ice and centrifuged (Sorvall RC6 plus $3220 \mathrm{~g}, 30 \mathrm{~min}, 4^{\circ} \mathrm{C}$ ). The supernatant (CS hydrolyzate) was recovered and analyzed for sugar and phenolic content before detoxification. The solid residue was washed twice with $150 \mathrm{~mL}$ of deionized water (total volume) and centrifuged at the same conditions described above, before being dried at $55^{\circ} \mathrm{C}$ until reaching a constant weight.

\subsection{Detoxification of the CS Hydrolyzate}

The CS hydrolyzate detoxification was carried out using AC at three different concentrations: 5\%, $10 \%$ and $20 \%(w / v)$. For $5 \%$ and $10 \%$ detoxification, the charcoal was added to the CS hydrolyzate and put on a shaker incubator at $25^{\circ} \mathrm{C}$ for $1 \mathrm{~h}$ at $180 \mathrm{rpm}$. For $20 \%$ detoxification, the charcoal was added to the CS hydrolyzate and placed on a Vortex Mixer (Heidolph, Schwabach, Germany) for $1 \mathrm{~h}$ at room temperature. Each detoxified hydrolyzate was centrifuged (Eppendorf 5415R centrifuge, 14,300 g, $45 \mathrm{~min}, 4^{\circ} \mathrm{C}$ ) for separate recovery of the hydrolyzate and AC. The detoxified CS hydrolyzates were characterized for sugars and total phenols as reported below. All the experiments were conducted in triplicate and results were expressed as mean \pm standard deviation (SD).

\subsection{Desorption of Phenolic Compounds from the Charcoal}

The phenolic compounds adsorbed on the $\mathrm{AC}$ were recovered with the following eluting solutions: water, $0.5 \mathrm{M}$ sodium hydroxide, $1 \mathrm{M}$ sodium hydroxide, alkaline ethanol ( $\mathrm{pH} 11.0$ adjusted with sodium hydroxide), and $2 \mathrm{M}$ sodium hydroxide/ethanol (1:1 v/v). Briefly, AC from the detoxification stage was oven-dried at $70^{\circ} \mathrm{C}$ for $4 \mathrm{~h}$; then, a volume of eluent corresponding to the double volume of the detoxified CS hydrolyzate was added to the $\mathrm{AC}$, and incubated at $70{ }^{\circ} \mathrm{C}$ for $2 \mathrm{~h}$ under continuous stirring. The mixture was centrifuged (Sorvall RC6 plus 34,220 $\mathrm{g}, 1 \mathrm{~h}, 4^{\circ} \mathrm{C}$ ), and the supernatant was separated from the AC and further centrifuged to remove any residual charcoal particles. The AC 
from both centrifugation steps was pooled and submitted to a second elution process, at the same conditions, to maximize the recovery of phenolic compounds.

The phenolic compounds desorbed from the AC were quantified by the Folin-Ciocalteu method, as described in Section 3.7, whereas those still adsorbed on AC were determined by difference between the total phenols in the crude CS hydrolyzate and the total phenols recovered in the detoxified CS hydrolyzate. The desorption yield was calculated according to Equation (1). All experiments were conducted in triplicate and results were expressed as mean $\pm \mathrm{SD}$.

$$
\begin{gathered}
\text { D yield }(\%)=\left[\frac{\text { mass of total phenols in the AC eluates }}{\text { mass of total phenols adsorbed in AC }}\right] \times 100= \\
\text { mass of total phenols in the AC eluates }
\end{gathered}
$$

\subsection{Fermentation of the Detoxified CS Hydrolyzate}

The microorganism used in this study was C. butyricum DSM 10702 from the German Collection of Microorganisms and Cell Cultures (DSMZ, Braunschweig, Germany). The strain was pre-cultured in Reinforced Clostridial Medium (RCM, Difco ${ }^{\mathrm{TM}}$, Le Pont de Claix, France) at $37^{\circ} \mathrm{C}$ for $16 \mathrm{~h}$ and used for inoculating (at $1 \%(v / v)$ ) the anoxic fermentation medium, composed by trypticase soy broth without dextrose, yeast nitrogen base, oligoelements, minerals, redox indicator and cysteine hydrochloride [48]. The detoxified CS hydrolyzate was used as carbon and energy source in the fermentation medium.

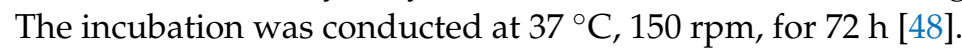

\subsection{Characterization of the samples}

The estimation of the sugars released from the enzymatic hydrolysis was carried out as previously described by Maurelli et al. [19]. The samples were analyzed by a high-performance liquid chromatographic HPLC system (Dionex, Sunnyvale, CA, USA), equipped with an anionic exchange column (Carbopac PA-100) and a pulsed electrochemical detector. Glucose and xylose were separated with $16 \mathrm{mM}$ sodium hydroxide at a flow rate of $0.25 \mathrm{~mL} / \mathrm{min}$, and identified by the respective standards. Fucose was used as internal standard. Total phenolic content was measured by the Folin-Ciocalteu method [60]. Variable volumes of samples, properly diluted to $150 \mu \mathrm{L}$, were mixed with $750 \mu \mathrm{L}$ of Folin-Ciocalteu reagent (ten-fold diluted with deionized water), and $600 \mu \mathrm{L}$ of $7.5 \%$ $(w / v) \mathrm{Na}_{2} \mathrm{CO}_{3}$. Samples were kept in the dark at $25^{\circ} \mathrm{C}$ for $2 \mathrm{~h}$ and afterwards the absorbance was read at $765 \mathrm{~nm}$ in a Varian spectrophotometer (DMS-200, Varian Analytical Instruments, Leini, Torino, Italy). The phenolic content was calculated by a calibration curve obtained with increasing quantities of gallic acid standard solution ranging from 1.5 to $10 \mu \mathrm{g}$, and expressed as mg of GAE per liter of CS hydrolyzate.

The free radical scavenging capacity was evaluated by the DPPH assay following the method of Barreira et al. [61], with modifications. Prior to the assay, the $\mathrm{pH}$ of the samples was corrected to 7.0 with $37 \% \mathrm{HCl}(w / w)$. A volume of sample containing an amount of phenolic compounds corresponding to $20 \mu \mathrm{g}$ GAE was diluted to $150 \mu \mathrm{L}$ with deionized water, and mixed with $1.35 \mathrm{~mL}$ of $60 \mu \mathrm{M}$ DPPH dissolved in methanol. A control prepared with $150 \mu \mathrm{L}$ of deionized water and $1.35 \mathrm{~mL}$ of $60 \mu \mathrm{M}$ DPPH was also prepared. The samples and the control were read against a blank made of $150 \mu \mathrm{L}$ of deionized water and $1.35 \mathrm{~mL}$ of methanol. After $30 \mathrm{~min}$ of incubation at room temperature in the dark, the absorbance was read at $517 \mathrm{~nm}$. The data obtained were used to calculate the percentage of RSA according to Equation (2).

$$
\text { RSA }(\%)=\left(1-\frac{\text { Absorbance }_{\text {sample }}}{\text { Absorbance }_{\text {control }}}\right) \times 100
$$

The biogas samples were collected directly from the headspace of the serum flasks by using a gas-tight syringe and the produced $\mathrm{H}_{2}$ and $\mathrm{CO}_{2}$ were quantified by gas chromatography (GC). 
The GC was a Varian 430-GC equipped with TCD and a fused silica column (Select Permanent Gases $/ \mathrm{CO}_{2}$-Molsieve 5A/Borabound Q Tandem \#CP 7430). The injector and column were operated at $80^{\circ} \mathrm{C}$ and the detector at $120^{\circ} \mathrm{C}$. Argon was the carrier gas at a rate of $32.4 \mathrm{~mL} / \mathrm{min}$. The concentration of $\mathrm{H}_{2}$ and $\mathrm{CO}_{2}$ in the produced biogas and the $\mathrm{H}_{2}$ production yields were calculated as described in [62]. Total sugar concentration in the fermentation supernatants was determined by the phenol-sulfuric acid method using glucose as the reference monosaccharide [63]. The organic acids produced were characterized by HPLC analysis [48].

\section{Conclusions}

This study proposed a biorefinery model for CS upgrading, which takes advantage of the main constituents of this waste biomass, namely carbohydrates and phenolic compounds. Carbohydrates represent $41.6 \%$ of CS dry weight and were used as a fermentable substrate for the production of $\mathrm{H}_{2}$ and butyrate after alkaline pretreatment and enzymatic hydrolysis. The phenolic compounds amounted to $682 \mathrm{mg}$ GAE/L in the CS hydrolyzate and were extracted by AC adsorption in a detoxification stage prior to fermentation. This allowed the selective recovery of phenolic compounds with more than twice the RSA of that of the crude CS hydrolyzate and, at the same time, minimized disposal problems by the possibility of AC reuse. Based on the production of chestnut trees in 2014 in the Mediterranean basin, the upgrading of CS according to the proposed model would correspond to an annual recovery of up to 208 tons of phenolic compounds. The conversion of the sugars in the detoxified CS hydrolyzate by C. butyricum produced $63.9 \mathrm{~mL} \mathrm{H}_{2} / \mathrm{g} \mathrm{CS}$ and $18.9 \mathrm{mg}$ butyrate/g CS. The transposition of these yields into the amount of waste shells generated in the Mediterranean chestnut industry represents 530 and 160 tons/year of butyrate and $\mathrm{H}_{2}$, respectively. At the same time, up to 9140 tons/year of CS spent residue could be potentially used for heat and power generation.

The importance and dimension of the chestnut industry worldwide justifies the need to redirect a waste that is currently not valued to more noble and environmentally friendly uses. The proposed biorefinery model holds a promise for future optimization of the selective recovery of antioxidant molecules and the improvement of the CS carbohydrates conversion to energy and bioactive compounds.

Acknowledgments: The authors gratefully acknowledge the financial support by the Project FCT/CNR-Italia 128585955528141 and the Bilateral Cooperation Project FCT/IBAF-CNR 2015-2016. The authors would like to acknowledge José Carlos Roseiro, senior researcher at LNEG, for proof reading of the English in this article.

Author Contributions: All authors conceived and designed the experiments and the biorefinery model. Alessandra Morana prepared the chestnut shell hydrolyzate. Giuseppe Squillaci performed the recovery of phenolic compounds from charcoal and characterized the samples obtained for phenolic content and antioxidant activity. Susana M. Paixão and Luís Alves performed the detoxification of the chestnuts shells hydrolyzate using activated charcoal and analyzed the respective data. Francesco La Cara performed a critical evaluation of the data obtained. Patrícia Moura performed the fermentation experiments and analyzed the respective data. All authors contributed to the writing of the paper.

Conflicts of Interest: The authors declare no conflict of interest.

\section{References}

1. Ragauskas, A.J.; Williams, C.K.; Davison, B.H.; Britovsek, G.; Cairney, J.; Eckert, C.A.; Frederick, W.J., Jr.; Hallett, J.P.; Leak, D.J.; Liotta, C.L.; et al. The path forward for biofuels and biomaterials. Science 2006, 311, 484-489. [CrossRef] [PubMed]

2. Metger, J.O.; Huttermann, A. Sustainable global energy supply based on lignocellulosic biomass from afforestation of degraded areas. Naturwissenschaften 2009, 96, 279-288. [CrossRef] [PubMed]

3. Scarlat, N.; Martinov, M.; Dallemand, J.F. Assessment of the availability of agricultural crop residues in the European Union: Potential and limitations for bioenergy use. Waste Manag. 2010, 30, 1889-1897. [CrossRef] [PubMed] 
4. Costa Lopes, A.M.; Roseiro, L.B.; Lukasik, R.B. Relevance of ionic liquids and biomass feedstocks for biomolecule extraction. In Ionic Liquids in the Biorefinery Concept: Challenges and Perspectives; Lukasik, R.B., Ed.; RSC Green Chemistry No. 36; The Royal Society of Chemistry: Cambridge, UK, 2016; pp. 121-163.

5. Fiorentino, G.; Ripa, M.; Ulgiati, S. Chemicals from biomass: Technological versus environmental feasibility. A review. Biofuels Bioprod. Biorefin. 2017, 11, 195-214. [CrossRef]

6. Isikgor, F.H.; Becer, C.R. Lignocellulosic biomass: A sustainable platform for the production of bio-based chemicals and polymers. Polym. Chem. 2015, 6, 4497-4559. [CrossRef]

7. Cherubini, F.; Strømman, A.H. Production of biofuels and biochemicals from lignocellulosic biomass: Estimation of maximum theoretical yields and efficiencies using matrix algebra. Energy Fuels 2010, 24, 2657-2666. [CrossRef]

8. Bragança, H. 2007 Chestnut Blight in Portugal: Spread and Populational Structure of Cryphonectria parasitica. Ph.D. Thesis, Faculty of Sciences of Lisbon, Lisbon University, Lisbon, Portugal, 2007.

9. FAOSTAT, Food and Agriculture Organization of the United States. Available online: http://www.fao.org/ faostat/en/\#data (accessed on 26 September 2017).

10. Economic Study for the Development of the Chestnut Sector, Portuguese Forestry Forum, Report Project SIAC 02/23070/2011, 2011. Available online: http:/ / forumflorestal.pt/wp-content/uploads/2012/04/ Relatróio-Global-Castanha-versão-impressão.pdf (accessed on 26 September 2017).

11. Vázquez, G.; González-Alvarez, J.; Santos, J.; Freire, M.S.; Antorrena, G. Evaluation of potential applications for chestnut (Castanea sativa) shell and eucalyptus (Eucalyptus globulus) bark extracts. Ind. Crops Prod. 2009, 29, 364-370. [CrossRef]

12. Liberti, A.; Goretti, G.; Russo, M.V. PCDD and PCDF formation in the combustion of vegetable wastes. Chemosphere 1983, 12, 661-663. [CrossRef]

13. Wakefield, J.C. HPA-CHaPD-004-A Toxicological Review on the Products of Combustion, Health Protection Agency Chemical Research Reports. 2010; ISBN 978-0-85951-663-1. Available online: https:/ / www.gov.uk/ government/publications / combustion-products-a-toxicological-review (accessed on 29 August 2017).

14. De Vasconcelos, M.C.; Bennett, R.N.; Rosa, E.A.; Ferreira-Cardoso, J.V. Composition of European chestnut (Castanea sativa Mill.) and association with health effects: Fresh and processed products. J. Sci. Food Agric. 2010, 90, 1578-1589. [CrossRef] [PubMed]

15. Vázquez, G.; Fontenla, E.; Santos, J.; Freire, M.S.; González-Álvarez, J.; Antorrena, G. Antioxidant activity and phenolic content of chestnut (Castanea sativa) shell and eucalyptus (Eucalyptus globulus). Ind. Crops Prod. 2008, 28, 279-285. [CrossRef]

16. Vella, F.M.; Laratta, B.; La Cara, F.; Morana, A. Recovery of bioactive molecules from chestnut (Castanea sativa Mill.) by-product through eco-friendly extraction methods. Nat. Prod. Res. 2017. [CrossRef] [PubMed]

17. Ferri, M.; Bin, S.; Vallini, V.; Fava, F.; Michelini, E.; Roda, A.; Minnucci, G.; Bucchi, G.; Tassoni, A. Recovery of polyphenols from red grape pomace and assessment of their antioxidant and anti-cholesterol activities. New Biotechnol. 2016, 33, 338-344. [CrossRef] [PubMed]

18. Jung, B.S.; Lee, N.-K.; Na, D.S.; Yu, H.H.; Paik, H.-D. Comparative analysis of the antioxidant and anticancer activities of chestnut inner shell extracts prepared with various solvents. J. Sci. Food Agric. 2015, 96, 2097-2102. [CrossRef] [PubMed]

19. Maurelli, L.; Ionata, E.; La Cara, F.; Morana, A. Chestnut shell as unexploited source of fermentable sugars: Effect of different pretreatment methods on enzymatic saccharification. Appl. Biochem. Biotechnol. 2013, 170, 1104-1118. [CrossRef] [PubMed]

20. Sivagurunathana, P.; Kumar, G.; Mudhoo, A.; Rene, E.R.; Saratale, G.D.; Kobayashi, T.; Xu, K.; Kim, S.-H.; Kim, D.-H. Fermentative hydrogen production using lignocellulose biomass: An overview of pre-treatment methods, inhibitor effects and detoxification experiences. Renew. Sustain. Energy Rev. 2017, 77, $28-42$. [CrossRef]

21. Zhang, J.; Zang, L. Enhancement of biohydrogen production from brewers' spent grain by calcined-red mud pretreatment. Bioresour. Technol. 2016, 209, 73-79. [CrossRef] [PubMed]

22. Jiang, D.; Fang, Z.; Chin, S.-X.; Tian, X.-F.; Su, T.-C. Biohydrogen production from hydrolysates of selected tropical biomass wastes with Clostridium butyricum. Sci. Rep. 2016, 6, 27205. [CrossRef] [PubMed]

23. Schönicke, P.; Shahab, R.; Hamann, R.; Kamm, B. Microbial life on green biomass and their use for production of platform chemicals. In Microorganisms in Biorefineries (Microbiology Monographs 26); Kamm, B., Ed.; Springer: Berlin/Heidelberg, Germany, 2015; ISBN 978-3-662-45209-7. 
24. Zacharof, M.-P.; Vouzelaud, C.; Mandale, S.J.; Lovitt, R.W. Valorization of spent anaerobic digester effluents through production of platform chemicals using Clostridium butyricum. Biomass Bioenergy 2015, 81, 294-303. [CrossRef]

25. Jha, A.K.; Li, J.; Yuan, Y.; Baral, N.; Ai, B. A review on bio-butyric acid production and its optimization. Int. J. Agric. Biol. 2014, 16, 1019-1024.

26. Tai, J.; Adav, S.S.; Su, A.; Lee, D.-J. Biological hydrogen production from phenol-containing wastewater using Clostridium butyricum. Int. J. Hydrog. Energy 2010, 35, 13345-13349. [CrossRef]

27. Quéméneur, M.; Hamelin, J.; Barakat, A.; Steyer, J.-P.; Carrère, H.; Trably, E. Inhibition of fermentative hydrogen production by lignocellulose-derived compounds in mixed cultures. Int. J. Hydrog. Energy 2012, 37, 3150-3159. [CrossRef]

28. Ham, J.-S.; Kim, H.-Y.; Lim, S.-T. Antioxidant and deodorizing activities of phenolic components in chestnut inner shell extracts. Ind. Crops Prod. 2015, 73, 99-105. [CrossRef]

29. Li, S.; Chen, G.; Zhang, C.; Wu, M.; Wu, S.; Liu, Q. Research progress of natural antioxidants in foods for thetreatment of diseases. Food Sci. Hum. Wellness 2014, 3, 110-116. [CrossRef]

30. Martillanes, S.; Rocha-Pimienta, J.; Cabrera-Bañegil, M.; Martín-Vertedor, D.; Delgado-Adámez, J. Application of Phenolic Compounds for Food Preservation: Food Additive and Active Packaging. In Phenolic Compounds—Biological Activity; Soto-Hernández, M., Ed.; In Tech: Rijeka, Croatia, 2017.

31. Mosier, N.; Wyman, C.; Dale, B.; Elander, R.; Lee, Y.Y.; Holtzapple, M.; Ladisch, M. Features of promising technologies for pretreatment of lignocellulosic biomass. Bioresour. Technol. 2005, 96, 673-686. [CrossRef] [PubMed]

32. Persson, P.; Andersson, J.; Gorton, L.; Larsson, S.; Nilvebrant, N.O.; Jönsson, L.J. Effect of different forms of alkali treatment on specific fermentation inhibitors and on the fermentability of lignocellulose hydrolysates for production of fuel ethanol. J. Agric. Food Chem. 2002, 50, 5318-5325. [CrossRef] [PubMed]

33. Jönsson, L.J.; Alriksson, B.; Nilvebrant, N.O. Bioconversion of lignocellulose: Inhibitors and detoxification. Biotechnol. Biofuels 2013, 6, 16. [CrossRef] [PubMed]

34. Jönsson, L.J.; Martín, C. Pretreatment of lignocellulose: Formation of inhibitory by-products and strategies for minimizing their effects. Bioresour. Technol. 2016, 199, 103-112. [CrossRef] [PubMed]

35. Cantarella, M.; Cantarella, L.; Gallifuoco, A.; Spera, A.; Alfani, F. Comparison of different detoxification methods for steam-exploded poplar wood as a substrate for the bioproduction of ethanol in SHF and SSF. Proc. Biochem. 2004, 39, 1533-1542. [CrossRef]

36. Guo, X.; Cavka, A.; Jönsson, L.J.; Hong, F. Comparison of methods for detoxification of spruce hydrolysate for bacterial cellulose production. Microb. Cell Fact. 2013, 12, 93. [CrossRef] [PubMed]

37. Chandel, A.K.; Kapoor, R.K.; Singh, A.; Kuhad, R.C. Detoxification of sugarcane bagasse hydrolysate improves ethanol production by Candida shehatae NCIM 3501. Bioresour. Technol. 2007, 98, 1947-1950. [CrossRef] [PubMed]

38. Schroyen, M.; Van Hulle, S.W.H.; Holemans, S.; Vervaeren, H.; Raes, K. Laccase enzyme detoxifies hydrolysates and improves biogas production from hemp straw and miscanthus. Bioresour. Technol. 2017, 244, 597-604. [CrossRef] [PubMed]

39. Adeboye, P.T.; Bettiga, M.; Olsson, L. The chemical nature of phenolic compounds determines their toxicity and induces distinct physiological responses in Saccharomyces cerevisiae in lignocellulose hydrolysates. AMB Express 2014, 4, 46. [CrossRef] [PubMed]

40. Dai, J.; Mumper, R.J. Plant phenolics: Extraction, analysis and their antioxidant and anticancer properties. Molecules 2010, 15, 7313-7352. [CrossRef] [PubMed]

41. Nitiema, L.W.; Savadogo, A.; Simpore, J.; Dianou, D.; Traore, A.S. In vitro antimicrobial activity of some phenolic compounds (Coumarin and Quercetin) against gastroenteritis bacterial strains. Int. J. Microbiol. Res. 2012, 3, 183-187. [CrossRef]

42. Samad, N.B.; Debnath, T.; Hasnat, M.A.; Pervin, M.; Kim, D.H.; Jo, J.E.; Park, R.S.; Lim, B.O. Phenolic contents, antioxidant and anti-inflammatory activities of Asparagus cochinchinensis (Loureiro) Merrill. J. Food Biochem. 2014, 38, 83-91. [CrossRef]

43. Ena, A.; Pintucci, C.; Carlozzi, P. The recovery of polyphenols from olive mill waste using two adsorbing vegetable matrices. J. Biotechnol. 2012, 157, 573-577. [CrossRef] [PubMed]

44. Ozkaya, B. Adsorption and desorption of phenol on activated carbon and a comparison of isotherm models. J. Hazard. Mater. 2006, 129, 158-163. [CrossRef] [PubMed] 
45. Qadeer, R.; Rehan, A.H. A study of the adsorption of phenol by activated carbon from aqueous solutions. Turk. J. Chem. 2002, 26, 357-361.

46. Streicher, J.; Ruhl, A.S.; Gnirß, R.; Jekel, M. Where to dose powdered activated carbon in a wastewater treatment plant for organic micro-pollutant removal. Chemosphere 2016, 156, 88-94. [CrossRef] [PubMed]

47. Lo, Y.-C.; Lu, W.-C.; Chen, C.-Y.; Chang, J.-S. Dark fermentative hydrogen production from enzymatic hydrolysate of xylan and pretreated rice straw by Clostridium butyricum CGS5. Bioresour. Technol. 2010, 101, 5885-5891. [CrossRef] [PubMed]

48. Ortigueira, J.; Pinto, T.; Gouveia, L.; Moura, P. Production and storage of biohydrogen during sequential batch fermentation of Spirogyra hydrolyzate by Clostridium butyricum. Energy 2015, 88, 528-536. [CrossRef]

49. Beckers, L.; Masset, J.; Hamilton, C.; Delvigne, F.; Toye, D.; Crine, M.; Thonart, P.; Hiligsmann, S. Investigation of the links between mass transfer conditions, dissolved hydrogen concentration and biohydrogen production by the pure strain Clostridium butyricum CWBI1009. Biochem. Eng. J. 2015, 98, 18-28. [CrossRef]

50. Han, H.; Wei, L.; Liu, B.; Yang, H.; Shen, J. Optimization of biohydrogen production from soybean straw using anaerobic mixed bacteria. Int. J. Hydrog. Energy 2012, 37, 13200-13208. [CrossRef]

51. Kumar, G.; Bakonyi, P.; Periyasamy, S.; Kim, S.H.; Nemestóthy, N.; Bélafi-Bakó, K. Lignocellulose biohydrogen: Practical challenges and recent progress. Renew. Sustain. Energy Rev. 2015, 44, 728-737. [CrossRef]

52. Bastidas-Oyanedel, J.R.; Bonk, F.; Thomsen, M.H.; Schmidt, J.E. Dark fermentation biorefinery in the present and future (bio)chemical industry. Rev. Environ. Sci. Bio/Technol. 2015, 14, 473-498. [CrossRef]

53. Dwidar, M.; Park, J.-Y.; Mitchell, R.J.; Sang, B.-I. The future of butyric acid in industry. Sci. World J. 2012, 471417. [CrossRef] [PubMed]

54. Van den Berg, C.; Heeres, A.S.; van der Wielen, L.A.M.; Straathof, A.J.J. Simultaneous clostridial fermentation, lipase-catalyzed esterification, and ester extraction to enrich diesel with butyl butyrate. Biotechnol. Bioeng. 2013, 110, 137-142. [CrossRef] [PubMed]

55. Moura, P.; Valdez-Vazquez, I.; Saratale, G.D.; Saratale, R.G.; Silva, C.; Ortigueira, J. Dark fermentative hydrogen production: From concepts to a sustainable production. In Microbial Fuels: Technologies and Applications; Harzevili, F.D., Hiligsmann, S., Eds.; CRC Press: Boca Raton, FL, USA, 2017.

56. Özçimen, D.; Ersoy-Meriçboyu, A. A study on the carbonization of grapeseed and chestnut shell. Fuel Process. Technol. 2008, 89, 1041-1046. [CrossRef]

57. James, B.D.; DeSantis, D.A.; Moton, J.M.; Houchins, C. II.A.1 Hydrogen Pathways Analysis for Solid Oxide Fuel Cell (SOFC) and Dark Fermentation. Available online: https:/ /www.hydrogen.energy.gov/pdfs/ progress15/ii_a_1_james_2015.pdf (accessed on 26 September 2017).

58. Report Phytonutrients Market by Type (Carotenoids, Phytosterols, Flavonoids, Phenolic Compounds, and Vitamin E), Application (Food \& Beverage, Feed, Pharmaceutical, and Cosmetic), Source, \& by Region-Global Trends and Forecast to 2020. June 2015. Available online: Marketsandmarkets.com (accessed on 26 September 2017).

59. Zacharof, M.-P.; Lovitt, R.W. Recovery of volatile fatty acids (VFA) from complex waste effluents using membranes. Water Sci. Technol. 2014, 69, 495-503. [CrossRef] [PubMed]

60. Singleton, V.L.; Rossi, J.A., Jr. Colorimetry of total phenolics with phosphomolybdic-phosphotungstic acid reagents. Am. J. Enol. Vitic. 1965, 16, 144-158.

61. Barreira, J.C.M.; Ferreira, I.C.F.R.; Oliveira, M.B.P.P.; Pereira, J.A. Antioxidant activities of the extracts from chestnut flower, leaf, skins and fruit. Food Chem. 2008, 107, 1106-1113. [CrossRef]

62. Ortigueira, J.; Alves, L.; Gouveia, L.; Moura, P. Third generation biohydrogen production by Clostridium butyricum and adapted mixed cultures from Scenedesmus obliquus microalga biomass. Fuel 2015, 153, 128-134. [CrossRef]

63. Dubois, M.; Gilles, K.A.; Hamilton, J.K.; Rebers, P.A.; Smith, F. Colorimetric method for determination of sugars and related substances. Anal. Chem. 1956, 28, 350-356. [CrossRef]

(C) 2017 by the authors. Licensee MDPI, Basel, Switzerland. This article is an open access article distributed under the terms and conditions of the Creative Commons Attribution (CC BY) license (http:/ / creativecommons.org/licenses/by/4.0/). 